\title{
DIOS, PATRIA Y HOGAR. LA TRILOGÍA EN LA EDUCACIÓN DE LAS MUJERES
}

\author{
POR \\ Teresa González Pérez \\ Universidad de La Laguna
}

\begin{abstract}
RESUMEN
El régimen dictatorial de Franco estaba basado en principios de autoridad y jerarquía patriarcal con notoria incidencia en las relaciones sociales. El discurso ideológico apoyado por la iglesia estuvo subyacente en toda la actividad pública y privada. La imagen de las mujeres era la misma que habían tenido en tiempos ancestrales, pero en este momento con unas motivaciones ideológicas que perseguían convertirlas en garantes y legitimadoras del régimen a través de la familia. Con el apoyo de la Iglesia y la Sección Femenina se mitificó el modelo de mujer sustentado en la trilogía Dios, Patria y Hogar. La educación construyó el prototipo de mujer apoyado en el discurso tradicional católico que se perpetuó a lo largo de toda la dictadura.
\end{abstract}

Palabras ClaVE: Dictadura, iglesia, mujeres, Sección Femenina, educación, nacional-catolicismo.

\section{GOD, COUNTRY AND HOME. THE TRILOGY IN THE EDUCATION OF WOMEN}

\begin{abstract}
Franco's dictatorial regime was based on principles of authority and patriarchal hierarchy noticeable impact on social relations. The ideological discourse supported by the church was underlying all the public and private activity. The image of women was the same as they had in ancient times, but this time with a turn ideological motivations in pursuing guarantors and legitimacy of the regime through the family. With the support of the Church and the Women's Section was mythologized female model supported in the trilogy God, Country and Home. Education built the prototype of a woman leaning on the traditional Catholic discourse is perpetuated throughout the dictatorship.
\end{abstract}

KEY WORDS: Dictatorship, church, women, Women's Section, Education, National-Catholicism. 
$\begin{array}{ll}\text { Recibido/Received } & 19-01-2012 \\ \text { Aceptado/Accepted } & 27-04-2012\end{array}$

En España la dictadura militar se prolongó por un espacio de tiempo aproximado de cuarenta años (1936-1975). Aunque con el fracaso del golpe de estado y el enfrentamiento civil hubo variantes geográficas en la medida que no todas las zonas quedaron bajo el poder de los militares desde 1936 sino según avanzaban las tropas rebeldes. Un ciclo histórico con rasgos propios de los modelos políticos fascistas, que exaltaba los principios de la religión y la moral cristiana junto a los valores del patriotismo. La iglesia legitimó el levantamiento militar y la guerra civil como cruzada afianzando el nacional-catolicismo. Recuperó sus poderes tradicionales, afirmó la confesionalidad del estado, impuso sus dogmas y estrechó el vínculo del integrismo católico con la sociedad conservadora. Desde los comienzos de la contienda se inició la política del nuevo régimen autoritario. En su proceso fue generador de desigualdades económicas y sociales, así como de unas relaciones sociales marcadas por las diferencias de clase y de género. Unos años difíciles pero ideológicamente fuertes y adoctrinadores que, respondiendo a los postulados oficiales del nacional catolicismo, marcaron los destinos de los españoles. La primera etapa del franquismo se corresponde con la política económica de autarquía caracterizada por el hambre y la miseria. Las mujeres constituyeron una pieza clave en la consolidación del sistema a nivel social y económico. Fueron utilizadas para reproducir y perpetuar los valores del régimen en el ámbito de lo privado. Cumplían con las tareas de reproducción social en el seno del hogar bajo el control ideológico y la represión del orden patriarcal.

La subordinación marcada por la política uniformadora del régimen tuteló a las españolas que asumieron el modelo hogareño de esposa y madre de acuerdo con los principios patriarcales. El aparato ideológico del franquismo constreñía los derechos de las mujeres. Su misión estaba en el hogar, lugar donde cumplir su único destino, el matrimonio y la maternidad. No obstante, tenía espacios fuera del hogar que las hacía visibles como las acciones de beneficencia y caridad que desarrollaban vinculadas a la Iglesia. La participación en las congregaciones marianas, en Acción Católica y movimientos apostólicos permitieron otras formas de socialización sin romper con el ideal femenino. Otra plataforma de presencia fue la Sección Femenina a través de cuya acción canalizaron múltiples actividades.

La Sección Femenina como organización falangista emprendió la tarea formativa, construyendo el nuevo modelo de mujer sustentado en el discurso tradicional católico. La vida de las mujeres se desenvolvió en un ambiente de control social y bajo la atenta mirada de la iglesia. Marginadas en los espacios públicos pero con amplias competencias en el mundo privado debían atenerse al orden establecido. El ideal de formación de las mujeres se extendió hasta el 
fallecimiento del dictador y se centraba en la trilogía Dios, Patria y Hogar. A lo largo de los años la sociedad franquista condicionó la educación para las mujeres. Tanto el sexismo como las diferencias de género persistieron en los diferentes niveles educativos pero las mujeres fueron accediendo a la educación. De forma paulatina se fue visualizando el aumento de la escolarización de las niñas aunque se mantuvo la desigual trayectoria educativa inter géneros.

En este artículo pretendemos acercarnos a la educación de las mujeres contextualizando y analizando las prácticas en la primera etapa de la dictadura franquista, regidas por la influencia de la falange y de la iglesia. Nuestro objetivo es indagar en la formación de las mujeres en Canarias desde la óptica del ideario franquista, analizando las acciones educativas desde los comienzos de la rebelión militar. Para esta investigación hemos seguido el patrón metodológico de la historiografía educativa contemporánea. En la heurística hemos empleado la metodología de análisis de la prensa y fuentes documentales para recabar la información y proceder a la tarea de la hermenéutica o interpretación de los datos. Para la realización de este trabajo consultamos los fondos de la Sección Femenina custodiados en los Archivos Históricos Provinciales de Las Palmas de Gran Canaria (AHPLPGC) y de Santa Cruz de Tenerife (AHPSCT), así como diferentes periódicos editados en ambas provincias insulares. Señalar al respecto los periódicos Amanecer (Diario de la revolución Nacional Sindicalista, editado en Santa Cruz de Tenerife), El Día (Diario de la mañana. Órgano del Movimiento Nacional Sindicalista, editado en Santa Cruz de Tenerife), Escuela Azul (Órgano del Sindicato Español de Magisterio, Santa Cruz de Tenerife), Gaceta de Tenerife (Diario católico, Santa Cruz de Tenerife), La Falange y Alerta (editados en Las Palmas). También consultamos la Revista Medina y la Revista Consigna (órganos de la Sección Femenina publicados en Madrid), así como documentos varios editados por la Sección Femenina. Las fuentes de información de la época presentan una carga ideológica determinante.

\section{LAS MUJERES NACIONALES EN EL ORDENAMIENTO POLÍTICO}

El franquismo fue un largo periodo determinado por su carácter autoritario y la exaltación de los valores postulados por la iglesia y los sectores conservadores de la sociedad. Se apoyó en la Falange, organización política paraestatal, para difundir de forma dogmática las ideas patriotas. Además bajo el mando militar de los sublevados actuó en la retaguardia de forma sectaria y asumió tareas represivas. ${ }^{1}$ En 1940 creó el Frente de Juventudes, organización falangista a la que tenían que afiliarse los niños/as y jóvenes entre los ocho y dieciocho años de forma obligatoria.

\footnotetext{
${ }^{1}$ Payne, S. G. 1997. El régimen de Franco. 1936-1975. Madrid: Alianza Editorial: 387.
} 
La Sección Femenina de la Falange Española Tradicionalista y de las Juntas Ofensivas Nacional Sindicalista (JONS) creada en 1934 mantuvo vigente su actividad hasta 1977, cuando se suprimió después de muerto el dictador. ${ }^{2}$ Era la versión femenina de la Falange Española Tradicionalista y de las JONS. Una institución clave en la sociedad de la posguerra, pues el decreto de $1939^{3}$ encomendó a la Sección Femenina la formación de las mujeres, tanto en el terreno doméstico como político-social, dentro de cuyo programa se incluía el servicio social. ${ }^{4}$ Este decreto fue firmado por Francisco Franco donde explicitaba la función asignada «En atención solícita que esta Jefatura Nacional dedica a la reorganización del Partido, ocupa lugar preeminente la Sección Femenina, por los méritos que sus afiliadas contrajeron durante la guerra en abnegado servicio, de asistencia y hermandad, que es, al propio tiempo, esperanza y promesa de cuanto la mujer española debe realizar ahora en los tiempos difíciles de la post-guerra. Con magnífica disciplina y admirable temple y delicadeza, la Sección Femenina ha llevado a cabo una misión insustituible en las Instituciones de Auxilio Social, Hospitales, Talleres, Lavaderos del Frente, Polvorines, etc. Ejemplar prestación guerrera y política que en nada ha disminuido las tradicionales virtudes de la mujer española, antes bien, las ha exaltado al calor de una profunda educación religiosa y patriótica, que ha constituido incesante preocupación para la Sección Femenina, en su anhelo hacia una total formación espiritual de la mujer».

El propio dictador, Francisco Franco Bahamonde, en su discurso con motivo de la conmemoración de la victoria, celebrada en Medina del Campo el 30 de mayo de 1939, insistió en que el objetivo de la Sección Femenina era «reconquistar el hogar para la mujer». Hacia su consecución se encaminó Pilar Primo de Rivera, alma máter de la organización. Sin embargo, en Canarias se inició desde 1936, al quedar el archipiélago bajo control de los militares sublevados. Esta institución paraestatal se ocupó de todas las cuestiones relativas a las mujeres, asumiendo atribuciones de adoctrinamiento ideológico, docente y cultural, además de abarcar el plano familiar. Preparaba a las mujeres como futuras madres, insistiendo en la higiene y el deporte para conseguir madres saludables y fuertes que gestaran hijos sanos. ${ }^{5}$ Insistía en el total respeto a la figura masculina y acatamiento de su opinión. Los criterios y decisiones de las mujeres eran las del marido.

${ }^{2}$ Por Decreto-Ley de 1 de abril de 1977 se disolvió la Sección Femenina. Por el mismo Decreto se disolvieron todas las organizaciones vinculadas al Movimiento Nacional que condujo al franquismo. Primo de Rivera, P. 1983. Recuerdos de una vida. Madrid: Ediciones Dyrsa.

${ }^{3}$ Decreto de la Jefatura del Estado, de 28 de diciembre de 1939, sobre funciones de la Sección Femenina de Falange Española Tradicionalista y de las JONS.

${ }^{4}$ El Decreto de 7 de octubre de 1937 configuró las bases jurídicas de la organización y estableció para las mujeres españolas el «deber nacional» de prestación del «Servicio Social».

${ }^{5}$ Campo, S. del. 1974. «Política demográfica de la familia y de la natalidad en España». Revista Sistema 4: 47-73.

Hispania Sacra, LXVI

133, enero-junio 2014, 337-363, ISSN: 0018-215X, doi: 10.3989/hs.2013.055 


\section{LA AMPLIACIÓN DE LA SECCIÓN FEMENINA}

La Falange como organización no obtuvo una respuesta destacada en el Archipiélago Canario antes del 18 de julio. Las afiliaciones a la Falange en Canarias antes de la rebelión militar fueron bajas. ${ }^{6}$ Las inscripciones de mujeres a la Sección Femenina resultaron igualmente poco significativas. En la isla de La Palma hubo mayor número de afiliaciones a la Falange que en Tenerife y en Gran Canaria. Con anterioridad apenas se hizo visible la acción de las mujeres falangistas. Realmente su despliegue tuvo lugar después del golpe de estado y el avance de la sublevación militar. La Sección Femenina en Canarias estaba organizada de acuerdo con los dictados nacionales. En el Archipiélago funcionaba la Delegación Provincial de la Sección Femenina de Santa Cruz de Tenerife y la Delegación Provincial de la Sección Femenina de Las Palmas, así como diferentes delegaciones locales. También delegaciones insulares y locales en cada una de las islas (Lanzarote, Fuerteventura, El Hierro y La Gomera) que se organizaron a partir del verano de $1936 .^{7}$ En Santa Cruz de Tenerife se organizó la Sección Femenina provincial en agosto de 1936 con medio centenar de afiliadas. Más tarde se fueron organizando las comisiones locales y extendiéndose por los distintos pueblos de la geografía insular. ${ }^{8}$ Durante el primer y segundo año se creó un importante número de delegaciones locales. Incluso en pequeños núcleos de población y en algunos barrios se abrieron sedes de la Sección Femenina. ${ }^{9}$ Las delegaciones se fueron expandiendo de forma progresiva por otros pueblos y por otras islas, como sucedió en La Palma y Gran Canaria. En La Gomera y en El Hierro funcionaban delegaciones desde 1937. ${ }^{10}$ Las adscripciones insulares crecieron de forma paulatina y para abril de 1937 la cifra ascendía a 242 afiliadas y 154 flechas femeninas. ${ }^{11}$ La prensa diaria afecta a los sublevados daba cuenta desde sus páginas de la expansión de las organizaciones femeninas y de la apertura de locales. ${ }^{12}$

Las mujeres que ingresaron en las filas de la Sección Femenina en Canarias, normalmente, eran jóvenes provenientes de familias de clase media y alta; se

${ }^{6}$ Guerra Palmero, R. 2007. La Falange en Canarias (1936-1950). Santa Cruz de Tenerife: CCPC, pp. 26-27.

7 AHPSCT. Archivo Histórico Provincial de Santa Cruz de Tenerife. Delegación Provincial de la Sección Femenina. Sección Secretaría Provincial. Libros de Actas. AHPLPGC. Archivo Histórico Provincial de las Palmas de Gran Canaria. Administración Central Periférica. Fondo documental de la Sección Femenina. Documentación Administrativa, Servicios Sociales y Escuela Hogar (1938-1982).

${ }^{8}$ AHPSCT. Fondo Sección Femenina. Informe del Consejo Provincial. Años 1936-1977. Registros de entrada de correspondencia (1936-1939). Registros de salida de correspondencia (1936-1939).

${ }^{9}$ Ibídem.

${ }^{10}$ Ibídem.

${ }^{11}$ Guerra Palmero, R. 2007:49.

${ }^{12}$ Gaceta de Tenerife. Santa Cruz de Tenerife, 1 de noviembre de 1936. 
incorporaron de forma voluntaria y activa para colaborar en la «salvación de la patria». La heterogeneidad de las afiliaciones demostraba la necesidad de alistarse de algunas mujeres «no convencidas» como forma de garantizar su adhesión a los sublevados y evitar ser perseguidas o mal vistas. También fue una manera de romper el aislamiento doméstico en el que las colocaban los nuevos postulados del régimen. La relación de los cargos se daba a conocer desde las páginas de los periódicos locales a partir de la nota de prensa que facilitaba la Regidora de prensa y propaganda. ${ }^{13}$ Indicaban nombre y apellidos y cargo que ostentaba las camaradas. En los listados observamos cómo mujeres de la misma familia ostentaban diferentes cargos de responsabilidad. Su sintonía con el ideario falangista y su adhesión total la desplegaron también en su compromiso de socialización y educación de las mujeres. Sus principios ideológicos calaron entre la población, incluso en la prensa se exaltaban los valores tradicionales de la mujer española así como el espíritu de sacrificio y entrega a la causa nacional. ${ }^{14}$

Las camaradas de la Sección Femenina vestidas con el uniforme obligatorio afrontaban diversas actividades como tributo a la patria. Igualmente participaban en diferentes manifestaciones patrióticas haciendo gala de su adhesión a la «causa nacional». Ataviadas con su uniforme asistían a los actos religiosos, a las celebraciones del día del caudillo, a la festividad de la patrona Santa Teresa y otras conmemoraciones. Tanto en la asistencia a las misas como a los desfiles militares se significaban con su presencia. Anualmente preparaban diversos actos para honrar a su patrona, función religiosa, clausura de cursos, inauguración de determinadas obras o instituciones, encuentros deportivos, exposiciones de manualidades, festivales en el Teatro Pérez Galdós (Las Palmas) o en el Teatro Guimerá (Santa Cruz de Tenerife) por ejemplo. También en otros pueblos las delegaciones locales y en otras islas las delegaciones insulares y locales secundaban las celebraciones y festejos con motivo de la onomástica de la patrona. Por otra parte realizaban campañas de vacunación, cuestaciones, repartos de canastillas para bebes, juguetes, ropas y comida.

Dada la jerarquización de su estructura organizativa las delegaciones provinciales apenas tenían autonomía. La dependencia de los órganos superiores garantizaba el adecuado funcionamiento, de manera que había una estrecha dependencia de la Delegación Nacional. Incluso los nombramientos de cargos se hacían desde la jefatura nacional. Pilar Primo de Rivera era quien nombraba

\footnotetext{
${ }_{13}$ «Amanecer«, el día 26 de junio de 1938.

${ }^{14}$ Lennar de Alonso, D. 1936. «La Mujer en la Nueva España». Gaceta de Tenerife. Santa Cruz de Tenerife, 1 de noviembre; Membiela Vidal, L. 1938. «Mujeres Azules». Gaceta de Tenerife. Santa Cruz de Tenerife, 4 de enero. Otros artículos resaltaban el papel femenino, tales como: «Mujeres». 1936. La Falange, Las Palmas 7 de diciembre; «Madre Patria». 1937. La Falange. Las Palmas, 23 de julio. «La madre y el niño». 1937. La Falange. Las Palmas, 27 de julio.
}

Hispania Sacra, LXVI

133, enero-junio 2014, 337-363, ISSN: 0018-215X, doi: 10.3989/hs.2013.055 
a las delegadas provinciales o bien las cesaba en el cargo. Conocía a las delegadas a través de los continuos viajes y cursos de formación que realizaban a escala nacional para los mandos. La jefatura provincial estaba compuesta por la delegada jefe, la secretaria provincial y todas las delegadas provinciales. Las delegaciones locales de los principales núcleos urbanos en las islas de Tenerife (Santa Cruz y La Laguna), Gran Canaria (Las Palmas y Telde), y las delegaciones insulares de Lanzarote (Arrecife), Fuerteventura (Puerto del Rosario), La Palma (Santa Cruz de La Palma), El Hierro (Valverde) y La Gomera (Hermigua) quedaban en segundo nivel dentro de la dirección provincial. En el tercer nivel de la jefatura se hallaban las delegaciones locales de todos los pueblos de las islas en las respectivas provincias. ${ }^{15}$

La falange femenina insular mantenía una perfecta organización. Cada semana celebraba juntas donde las regidoras tomaban acuerdos y resoluciones sobre su cometido. ${ }^{16}$ Las conexiones con la sede central eran estrechas y la correspondencia fluida. En ningún momento se descuidó la comunicación pese a la lejanía del territorio insular, pues constituían una pieza clave en la formación de las mujeres canarias. Los continuos viajes que realizaban a Madrid mantenían activa la relación. ${ }^{17}$ Algunas isleñas se desplazaron a Madrid para prestar servicios, citar en este sentido que en 1937 se trasladaron a colaborar con la institución a nivel nacional. ${ }^{18}$

La campaña propagandística a través de la prensa y la radio, junto a la lejanía de los escenarios bélicos permitió poner en marcha toda la infraestructura, publicitar sus actividades a modo de propaganda y adoctrinamiento fascista. También por medio de la prensa se daba cuenta de las actividades de la Sección Femenina, en especial sus propios voceros informaban de su programación al tiempo que realizaban proclamas de acuerdo con los principios falangistas. ${ }^{19}$ Además de fomentar el patriotismo sensibilizaban a las mujeres con la causa militar en aras de realizar «sacrificios» en pro de la patria, como madres, esposas o novias, como enfermeras en los frentes de guerra o bien participando activamente desde la retaguardia. ${ }^{20}$ Las llamadas al sacrificio para recobrar el

${ }^{15}$ AHPSCT. Delegación Provincial de la Sección Femenina. Sección Secretaría Provincial. AHPLPGC. Administración Central Periférica. Fondo documental de la Sección Femenina.

${ }^{16}$ AHPSCT. Ibídem. Libros de Actas. AHPLPGC. Ibídem. Documentación Administrativa, Servicios Sociales y Escuela Hogar (1938-1982).

${ }^{17}$ AHPSCT. Fondo Sección Femenina. Informes del Consejo Provincial (1936-1977).

${ }^{18}$ Ibídem. Secretaria Provincial. Registro de entrada de correspondencia. Envío de camaradas para trabajar en la Sección Nacional (Fecha: 9 de octubre de 1937).

${ }^{19}$ González Alonso, G. 1937. «La perfecta falangista», Amanecer, Santa Cruz de Tenerife, 21 de diciembre; Elien. 1938. «Mujeres Azules» Gaceta de Tenerife, Santa Cruz de Tenerife, 4 de enero; Elien. 1938. ¡Mujeres azules! Santa Cruz de Tenerife, 4 de diciembre.

${ }^{20}$ Gaceta de Tenerife. 1936. Santa Cruz de Tenerife, 7, 10, 11 y 31 de octubre. 
ímpetu y la alegría de España obtenían respuesta dado que se trataba de colaborar para evitar estar «bajo sospecha». La Sección Femenina de Las Palmas (Gran Canaria) estableció que todos los jueves de cada semana, mientras durara la guerra, tenían que llevar un donativo a la Sección Femenina, que ninguna dijera que no podía «Ellos pueden pasar todo y hasta morir por España. Nosotras podemos sacrificar algún capricho y ahorrar algún gasto para ellos». ${ }^{21}$ También hicieron exaltaciones patrióticas destacando la importancia de las acciones emprendidas por las mujeres. ${ }^{22}$ Como ejemplo señalar el rótulo de «actividades eficientes» que publicaba el periódico Falange editado en Las Palmas. ${ }^{23}$ Así mismo las emisoras de radio emitían programas dirigidos a las mujeres. ${ }^{24}$

\section{UN DESPLIEGUE MÁS ALLÁ DEL HOGAR}

Durante el conflicto bélico las mujeres en Canarias desplegaron una intensa actividad y se implicaron de diversa manera en la vida cotidiana. La experiencia en la retaguardia dependió de la afiliación política. Las afectas al nuevo orden se ocuparon de desarrollar diferentes tareas en un medio social que las favorecía pese a las adversidades de un país en guerra. A pesar de la distancia de las islas de los frentes de batalla las mujeres tuvieron contacto con el ejército y se comprometieron en la retaguardia. ${ }^{25}$ En sus respectivas localidades las mujeres comenzaron a realizar acciones de apoyo a los soldados que estaban en los frentes de guerra, como recaudar dinero y joyas entre la población, representar obras de teatro y veladas artísticas para recoger donativos. ${ }^{26}$ También gestionaron las cocinas económicas, así como la contribución con el plato único y el día sin postre a efectos de aportar su coste. Además de trabajar en los talleres de costura confeccionando uniformes, vendajes, sábanas, abrigos, etc. ${ }^{27}$ Se difundía

${ }^{21}$ Madre Patria. 1937. La Falange, Las Palmas, 23 de julio.

22 Ídem.

${ }^{23}$ Falange. 1937. Las Palmas, 21 de abril, 27 de julio. Falange. 1938. 14 de septiembre.

${ }^{24}$ La delegación provincial del Frente de Juventudes emitía todos los sábados a las 6 de la tarde en Radio Las Palmas (EAJ 50 Las Palmas) el programa semanal de la «Voz del Frente de Juventudes» organizada por la Sección de Radio del Departamento Provincial de Cultura, Enseñanza y Propaganda. Cada sábado se publicaba la nota en el periódico Falange bajo la denominación «Boletín Provincial del Movimiento».

25 «Mujer, tú en la retaguardia, también contribuyes a la grandeza de España» (1938). Gaceta de Tenerife, 2 de marzo.

${ }^{26}$ AHPSCT. Fondo Sección Femenina. Informes del Consejo Provincial (1936-1977).

${ }^{27}$ Ibero, S.1936. «La mujer y la patria». La Patria, Santa Cruz de Tenerife, 2 de noviembre. Ibero, S. 1936. «La patria». La Patria, Santa Cruz de Tenerife, 9 de noviembre. En ambos escritos el autor hizo referencia al Taller patriótico creado en Santa Cruz de Tenerife y a la loable labor de las mujeres confeccionando diversas prendas y recogiendo donativos. También la Gaceta de Tenerife (1936), 8 y 20 de agosto, 7 y 8 de octubre, recogió los esfuerzos de las mujeres de la Sección Femenina. Igualmente el vocero La Falange (1937). Las Palmas de Gran Canaria, 23 de julio. 
el mensaje patriótico aleccionador insistiendo en que ellas también tenían que defender la patria. ${ }^{28}$

Además la Sección Femenina se encargó de impartir cursos de enfermeras, respondiendo a la llamada de los campos de batalla que necesitaban personal sanitario para atender a los militares heridos y/o enfermos. Desde los primeros meses de la contienda realizaron una labor de divulgación y captación entre las camaradas para comprometer simpatizantes con la causa..$^{29}$ Algunas falangistas se formaron como enfermeras en Santa Cruz de Tenerife o en Las Palmas para ir al frente como auxiliares en los hospitales de campaña, de la misma forma que hacían otras mujeres españolas sensibilizadas con la patria. ${ }^{30}$ La lejanía de la metrópoli y de los escenarios de guerra no fue impedimento para que las mujeres de Canarias acudieran a las zonas bélicas a prestar servicios como enfermeras. ${ }^{31}$

Desde 1936 se contaba con la implicación de las nuevas generaciones en la Sección Femenina. Las más jóvenes tenían un periodo de formación para realizar más tarde actividades que compartían con las jerarquías respectivas. A veces los flechas de ambos sexos participaban conjuntamente en actos de homenaje desde los primeros momentos. ${ }^{32}$ Cada celebración del día de San Fernando patrono de los Flechas, el 30 de mayo, se realizaban actos con la asistencia de mandos, autoridades y jerarquías de Falange masculina y femenina. También la asistencia de niños y niñas de las escuelas. De igual forma se realizaba en distintas localidades del archipiélago. Numeroso público se agolpaba a contemplar los respectivos homenajes «brazo en alto».

Cuando terminó la guerra se realizaron distintos homenajes al caudillo, entre ellos los realizados por los falangistas en Valladolid en los que participó la Sección Femenina de ambas provincias Canarias respondiendo a la llamada nacional. ${ }^{33}$ También en las islas se celebró el triunfo del ejército nacional y se hicieron homenajes al ejército. Al margen de que el archipiélago no fue escenario directo de la contienda pero sufrió sus consecuencias.

${ }^{28}$ «Madre Patria» (artículo firmado «Una hija de España. Segundo año triunfal de la Era Azul). 1937. La Falange. Las Palmas, el 28 de junio.

${ }^{29}$ AHPSCT. Fondo Sección Femenina. Informes del Consejo Provincial (1936-1977).

${ }^{30}$ Gaceta de Tenerife (1936). Santa Cruz de Tenerife, 31 de octubre.

${ }^{31}$ AHPSCT. Fondo Sección Femenina. Secretaria Provincial. Registro de entrada de correspondencia (1936-1938).

32 «El dos de mayo celebrado por los Flechas de Las Palmas». 1938. Alerta. Revista de las Juventudes Nacionalsindicalistas de Las Palmas. Gran Canaria, 1 de junio. (Tip. Falange-Las Palmas): 14.

${ }^{33}$ AHPSCT. Fondo Sección Femenina. Informes del Consejo Provincial (1936-1977). 


\section{OTRAS ACCIONES SOCIALES}

Desde los comienzos de la Sección Femenina realizaron tareas asistenciales. Ayudaban a la gente ensayando el populismo con un gesto generoso, porque en el archipiélago había muchas personas excluidas tanto procedentes de la clase obrera como campesina. ${ }^{34}$ Las falangistas atendieron a miles de niños en comedores sociales, y a miles de personas en las cocinas de hermandad o con reparto de alimentos. La acción de las mujeres franquistas en las islas abarcó labores de beneficencia. Ejercían una doble misión con los vencidos. A la vez que desarrollaban la caridad con las personas necesitadas ejercitaban la función reeducadora enseñándoles los postulados del nacional catolicismo. La generosidad llevaba implícita el mensaje adoctrinador como forma de garantizar su adhesión al régimen. ${ }^{35}$

El Auxilio Social se creó en ambas provincias insulares en 1936, a instancias de las mujeres de la Sección Femenina, con el objetivo de atender las necesidades más perentorias de la población. Formaba parte de la maquinaria del régimen pero hicieron a la vez acciones de beneficencia y control social, atendieron a las personas pobres sin recursos con repartos de comida y ropas. Desde su institucionalización realizaron un notable «apostolado» educativo, moral y religioso. Ayudaron a las familias perjudicadas por los acontecimientos bélicos, con las mujeres y los niños de los combatientes pero también con las viudas y los huérfanos, con las personas que no poseían medios económicos y se encontraban en situación de exclusión. En Tenerife pusieron en funcionamiento comedores infantiles, para ello hacían cuestaciones recaudando sumas de dinero, productos alimenticios y ropas con los donativos procedentes de todos los estamentos sociales, especialmente de la burguesía, empresarios y terratenientes.$^{36} \mathrm{En} \mathrm{La}$ Palma, La Gomera y en El Hierro de igual modo las falangistas se implicaron con la vecindad y crearon instituciones caritativas, a la vez que respondieron con ayuda humanitaria. En Gran Canaria llevaron a cabo igualmente una extensa labor de auxilio social. ${ }^{37} \mathrm{Su}$ preocupación por las clases menos favorecidas, por las mujeres y los niños lo atestigua el hecho de que había comedores infantiles y para madres lactantes. Por ejemplo, el comedor localizado en la calle Venegas, en Las Palmas, atendía el cuidado alimentario de la infancia. ${ }^{38}$ También repartían alimentos en la ciudad y los pueblos, incluso distribuyeron víveres en los pueblos de las islas de Lanzarote y Fuerteventura, aunque en estas islas también funcionaba el Auxilio Social dependiente de la Sección Femenina.

${ }^{34}$ El Día. 1939. Santa Cruz de Tenerife, 29 de octubre; Amanecer. 1936. Santa Cruz de Tenerife, 30 de diciembre.

${ }^{35}$ El Día. 1942. Santa Cruz de Tenerife, 4 de octubre.

${ }^{36}$ Amanecer. 1939. Santa Cruz de Tenerife, 4 de enero y 12 de febrero.

37 «Benemérita labor de Auxilio Social en Las Palmas». 1942. Falange. Las Palmas, 1 de octubre.

${ }^{38}$ Ibídem, 15 de octubre. 
Cabe destacar la labor de divulgación para la atención a los niños. A través de la Cartilla de la Madre enseñaban a las mujeres los saberes para la maternidad. Así cumplían con el objetivo de formación e instrucción en conocimientos de puericultura para que aprendieran el cuidado y la higiene infantil. El aprendizaje revestía de importancia. Las elevadas tasas de morbilidad entre la población infantil indican en parte problemas de ignorancia. En Tenerife en el Hogar de la Sagrada Familia de Santa Cruz de Tenerife se recogieron a menores en desamparo de forma permanente o temporal. Una obra benéfica que se ocupó de los niños desprotegidos, pobres o abandonados en las islas. Otra de las gestiones fue la apertura de la «Casa del Niño» en Las Palmas (Gran Canaria) para atender a la infancia que se hallaba en situación de abandono por diversas circunstancias. Según su cómputo inicial «recogerían a quinientos niños huérfanos y desamparados». ${ }^{39}$

Las guarderías infantiles fueron otra de las instituciones que propulsó la Sección Femenina en su larga trayectoria. Crearon guarderías en diversas ciudades españolas, entre ellas, se creó una en cada capital de las provincias insulares: una en Las Palmas y otra en Santa Cruz de Tenerife. Estos centros atendían la educación infantil entre los 0 y 6 años, respondiendo a objetivos asistenciales y formativos ${ }^{40}$ Tenían un horario amplio, desde las 8,30 de la mañana a 6,00 de la tarde. En este tiempo desarrollaban diversas actividades para los niños y niñas, tales como juegos, guiñol, teatro, pintura, jardinería, etc. además de prestar atención a la formación de las familias y difundir sus campañas de higiene.

\section{El MODELO DE MUJER CATÓLICA}

La iglesia católica fue la gran aliada del régimen, intervino en la educación y en el contexto familiar. ${ }^{41}$ De este modo, fijó las formas de relación y mantuvo en base a su origen divino la diferenciación entre hombres y mujeres, considerando la superioridad física e intelectual masculina ${ }^{42}$ Igualmente les asignaba roles distintos, prefijando una serie de conductas estereotipadas, aunque mantenía que tanto hombres como mujeres poseían cualidades propias pero a la vez complementarias.

\footnotetext{
39 Ibídem, 1 de octubre.

${ }^{40}$ Delegación Nacional de la Sección Femenina del Movimiento. 1968. La Sección Femenina del Movimiento en el desarrollo comunitario. Madrid, Sección Femenina: 42 y 43.

${ }^{41}$ Existen diversos trabajos que abordan la situación de las mujeres en este contexto, citar entre ellos a: Gallego Méndez, M. T. 1998. Mujer, Falange y Franquismo. Madrid, Taurus. Alcalde, M. 1999. Mujeres en el franquismo: Exiliadas, nacionalistas y opositoras. Barcelona, Flor del Viento. Nielfa Cristóbal, G. (Coord). 2003. Mujeres y Hombres en la España franquista: sociedad, economía, política, cultura. Madrid, Ed. Complutense.

${ }^{42}$ Roca i Girona, J. 1991. «Algunos elementos constitutivos del discurso dominante sobre la mujer en la posguerra española». En M. Nash y S. Tavera (Coord.). Las Mujeres y la Guerra Civil Española. Madrid: Ministerio de Cultura: 304 y 305.
} 
La misión de las mujeres se orientaba a la familia y a la maternidad. ${ }^{43} \mathrm{El}$ hombre era el cabeza de familia, situación que justificaba actitudes de dominio, a la vez que la reclusión de las féminas en el hogar tenía relación con el tradicionalismo católico que apoyaba el nuevo estado. La mujer estaba subordinada al hombre, que ocupaba por ley natural un rango superior en la familia. La subordinación al marido se consolidaba en el hecho de no poder disponer de dinero propio ni de capacidad legal para realizar ningún tipo de transacción económica. Necesitaba de la autorización del conyugue incluso para desempeñar actividad laboral remunerada, abrir una cuenta corriente o viajar. ${ }^{44}$ La moralización de las costumbres se extendió hasta la liberación del taller y del trabajo de las mujeres casadas y la prohibición del desempeño de profesiones liberales (decreto de marzo de 1938).

En 1938 se derogó la ley de matrimonio civil y la ley de divorcio con carácter retroactivo. El único matrimonio válido era el religioso santificado por la iglesia católica. En 1941 se contemplaban en el Código Penal los delitos de aborto, adulterio y concubinato. Se estableció la mayoría de edad a los 25 años obligando a las mujeres solteras a permanecer en el hogar paterno hasta casarse. ${ }^{45}$ El trabajo extradoméstico estaba penalizado. El marido cobraba un plus familiar con el objeto de que el salario fuera suficiente para la manutención del hogar, y así lo contemplaba la Ley del Subsidio familiar de 18 de julio de 1938 o la Ley de Ayuda familiar de marzo de 1948. La exaltación de la feminidad llegaba al extremo de insistir en que las mujeres destacadas intelectualmente lo habían hecho a costa de masculinizarse. Por otra parte, la actitud protectora de los hombres hacia las mujeres se entendía por la ausencia de éstas de la vida pública. ${ }^{46}$

Las fuerzas falangistas y la iglesia condicionaron la vida de las mujeres. ${ }^{47} \mathrm{En}$ la virgen María se mitificó el modelo mujer-madre que se presentaba a las niñas, con valores de sumisión y entrega. Se reafirmaba el modelo de madre con María, se anulaba a la mujer en función del papel y la imagen planteada: esposa y madre. En este sentido, al mismo tiempo que se mitificaba se menospreciaba a la mujer. El catolicismo integrista era antifeminista, presentaba a la mujer como ser sumiso, sólo capacitada para reproducir lo que el hombre le daba hecho, así lo manifestaba Pilar Primo de Rivera en el $1^{\circ}$ Congreso Nacional del S.E.M. celebrado en 1942. Se exaltaba el rol femenino de acuerdo con los postulados franquistas, en los que se incluía el papel tradicional de la familia y las tareas de las mujeres

${ }^{43}$ Valcárcel, A. 2000. Rebeldes hacia la paridad. Barcelona, Plaza \& Janés: 84-85.

${ }^{44}$ Toboso Sánchez, P. 2009. Las mujeres en el siglo xxi: Igualdad jurídica, discriminación cotidiana. En P. Pérez Cantó, P. (ed.) De la Democracia ateniense a la democracia paritaria. Barcelona: Icaria editorial: 211-213.

${ }^{45}$ VV.AA. 2000. Historia de las Mujeres. Sigo xx. Tomo $5^{\circ}$. Madrid: Taurus minor: 243.

${ }^{46}$ Primo de Rivera, P. 1983. Recuerdos de una vida. Madrid: Ediciones Dyrsa: 297.

${ }^{47}$ González Pérez, T. 2009. Los programas escolares y la transmisión de roles en el franquismo: La educación. Bordón, Vol. 61-3: 96.

Hispania Sacra, LXVI

133, enero-junio 2014, 337-363, ISSN: 0018-215X, doi: 10.3989/hs.2013.055 
en este ámbito, insistiendo sobre todo en la trasmisión de valores. ${ }^{48}$ En este sentido, cabía una preparación específica adoctrinando a las niñas. La formación en las actividades domésticas formaba parte del currículum elemental. ${ }^{49}$

La educación religiosa y la colaboración de las mujeres en actividades parroquiales fueron esenciales en su instrucción. Destacaban la catequesis, la beneficencia, la acción católica, la participación en rituales y ceremonias religiosas. La preparación para los quehaceres domésticos como esposa y madre junto a la formación política y social integraban el ideario de la Sección Femenina. La formación doméstica para las mujeres nacionalsindicalistas era el eje de actuación de la Sección Femenina y se afanaron en conseguirlo siguiendo el esquema diseñado por Pilar Primo de Rivera. Los postulados del régimen, que controlaba los destinos de España, sentenciaron a las mujeres a desempeñar como actividad exclusiva el servicio doméstico - de forma obligatoria y gratuita-, lugar adecuado para ejercer la profesión de madres y esposas, y mantener la subordinación a los hombres. El franquismo reforzó la desigualdad de género, la separación de roles y las diferencias curriculares con el aprendizaje de materias «mujeriles», confinando la función de las mujeres al espacio doméstico. La imagen de las mujeres era la misma que había tenido en tiempos ancestrales, pero en este momento con unas motivaciones ideológicas que perseguían convertirlas en garantes y legitimadoras del régimen a través de la familia. El discurso ideológico estuvo subyacente en toda la actividad pública y privada de la sociedad. Los mecanismos inhibidores y represores utilizados por el régimen como instrumento de legitimación fueron el dolor, sacrificio, pasividad y sumisión. Las instituciones Acción Católica y Sección Femenina fueron instrumentos empleados para la reeducación de las mujeres, caracterizados por la rigidez y la intransigencia. Acción Católica dependía directamente de la jerarquía eclesiástica y se hallaba vinculada a la actividad parroquial. Tuvo como misión principal velar por la moral social, tarea que atendía con una institución creada por el régimen: el Patronato de Protección a la Mujer. Dicho Patronato tenía asignadas una serie de Juntas Provinciales y Locales. Las Juntas Locales las componían el alcalde, el párroco y los vocales de la sección de moralidad de Acción Católica. Había que moralizarlo todo, y en esta lucha las mujeres desempeñaban un papel clave, manteniendo en su entorno la rigidez moral. Para ayudarlas en este cometido estaban las organizaciones apostólicas femeninas representadas por Acción Católica, que tenían presencia en todas las actividades religiosas de los seglares y en todos los actos de la vida social. Las agrupaciones femeninas tenían carácter subsidiario con respecto a las masculinas, y se proyectaron en las tareas de apostolado y en la instrucción de labores del hogar para niñas y jóvenes en las escuelas

\footnotetext{
48 «El caudillo y la mujer española».1946. Escuela Azul. Santa Cruz de Tenerife, 30 de enero.

${ }^{49}$ Escuela Azul. 1948. Santa Cruz de Tenerife, 10 de enero.
} 
taller, en las actividades de beneficencia y en campañas y cursos que fomentaban el modelo de mujer. ${ }^{50}$ Otras ramas de Acción Católica fueron la Juventud Obrera Femenina (JOFAC) y la Hermandad Obrera Femenina (HOFAC) que mantenían idéntica línea de actuación. En Canarias funcionaban Hogares Católicos donde los jóvenes se reunían y participaban en actos diversos. Fue espacio de socialización para la juventud isleña y de canalización de actividades.

Las jóvenes de clase media y alta, se instruían en colegios privados y participaban en actos religiosos-culturales y sociales (apostolado, meditación, ropero...). También se incluían llamadas de atención sobre la moda. Se defendía la moral y el recato. Dentro de la represión cultural y moral que dominaba la sociedad española no se impulsaba la lectura, excepto de obras religiosas. No era recomendable crear hábito lector. Se consideraba una actividad peligrosa porque podía provocar verdaderos trastornos de la personalidad a las mujeres. La iglesia no descuidó la formación de las mujeres ${ }^{51}$ Un ejemplo de ello lo constituyó el libro Mujeres de España escrito por fray Albino González y Menéndez Reigada, obispo de Tenerife (1924-1946), en el que presenta a las mujeres ejemplares. ${ }^{52} \mathrm{El}$ modelo de mujer que pretendía el gobierno fue asumido por los colegios privados, sobre todo religiosos, que representaban los intereses de las clases dominantes. En los años cuarenta las mujeres de la burguesía isleña eran las únicas que podían optar a una educación secundaria y adquirir cierta formación intelectual. Desde los años escolares se les modela según el prototipo de esposa y madre sumisa, señora educada y de buenos modales, pero no muy instruida, veladora de unos valores que garantizan la pervivencia del régimen.

\section{EDUCADAS PARA EL HOGAR Y LA PATRIA}

El discurso falangista determinó el modelo educativo de mujer que se proyectó en las disposiciones legislativas continuando el ámbito escolar con el currículum sexista que estableció la ley de instrucción pública de 1857. En la escolaridad obligatoria la ley de enseñanza primaria de 1945 incluyó una serie de disciplinas para instruir a las niñas y a las mujeres en la vida del hogar y en actividades afines

\footnotetext{
${ }^{50}$ Alted Vigil, A. 1991. «Las mujeres en la sociedad española de los años cuarenta», en M. Nash y S. Tavera (Coord.). Las Mujeres y la Guerra Civil Española. Madrid: Ministerio de Asuntos Sociales/Instituto de la Mujer: 296.

${ }^{51}$ González Menéndez-Reigada, A. 1940. Mujeres de España. Santa Cruz de Tenerife: Imprenta Católica.

${ }_{52}$ Escuela Azul. 1940. Santa Cruz de Tenerife, 10 de julio. Según el obispo tinerfeño se trataba de un libro de «vulgarización» que contiene veinticinco retratos a la pluma de mujeres ejemplares de nuestra raza. Su finalidad era «divulgar semblanzas de almas femeninas, señeras de nuestra Patria, dignas de admiración e imitación, que no han de ser sólo actrices y estrellas las que tengan de continuo ante los ojos nuestras mujeres y nuestras jóvenes contemporáneas».
}

Hispania Sacra, LXVI

133, enero-junio 2014, 337-363, ISSN: 0018-215X, doi: 10.3989/hs.2013.055 
con la esfera doméstica, con el propósito de preparar a una experta en el hogar. ${ }^{53}$ El Frente de Juventudes se instituyó dentro de la Sección Femenina para desplegar su tarea pedagógica. ${ }^{54} \mathrm{Se}$ le asignó la formación de las nuevas generaciones en los centros educativos y en los centros de trabajo. Según el artículo 10 de la ley del Frente de Juventudes: «Todos los alumnos de los Centros de Primera y Segunda Enseñanza, oficial y privada, forman parte del Frente de Juventudes».

En el Archipiélago Canario no se interrumpió la actividad académica, pese al estado de guerra, los centros educativos funcionaron con regularidad. El aparato escolar republicano fue desplazado hasta su total eliminación y sustituido por la escuela del modelo educativo autoritario. ${ }^{55} \mathrm{Un}$ «contramodelo escolar» que reivindicaba los valores religiosos y patrios propulsados por la iglesia y la falange, a la vez portavoces del nuevo orden instaurado por la fuerza de las armas.

Para garantizar el cumplimiento ideológico se creó el cargo de delegado de la autoridad militar en la enseñanza primaria, pública y privada, y en las Escuelas Normales del Archipiélago. ${ }^{56} \mathrm{Al}$ efecto se nombró delegado al capitán retirado del cuerpo de artillería Luis López de Ayala ${ }^{57}$ En estos momentos, los únicos protagonistas de la vida política y cultural fueron los alcaldes y gobernadores, designados por el gobierno nacional entre los falangistas locales más destacados ${ }^{58}$

De igual manera que en el resto del Estado, la enseñanza en Canarias mantuvo caracteres autoritarios tales como la confesionalidad y la centralización. La escolarización no fue un bien alcanzado por todas las niñas isleñas en los años cuarenta, cincuenta, incluso en los sesenta. En el escenario educativo del pasado siglo, cuando existían muchos núcleos rurales relativamente aislados, comunicados por

${ }^{53}$ Ley de enseñanza primaria de 17 de julio de 1945. Artículo 11: «la educación femenina preparará especialmente para la vida del hogar, artesanía e industrias domésticas». Colección Legislativa de Educación y Ciencia. Madrid: MEC, 1944-1945, p. 838-886. Vid. Flecha García, C. 1989. Algunos aspectos sobre la mujer en la política educativa durante el régimen de Franco. Revista Interuniversitaria de Historia de la Educación, $n^{\circ}$ 8: 77-98.

${ }^{54}$ Ley del Frente de Juventudes. 1940. 6 de diciembre. Artículo $1^{\circ}$. «En cumplimiento de los Estatutos de Falange Española Tradicionalista y de las JONS, se instituye el Frente de Juventudes para la formación y encuadramiento de las fuerzas juveniles de España. El Frente de Juventudes se organiza como una sección de FET y de las JONS».

55 Escolano Benito, A. 2002. La educación en la España contemporánea. Madrid: Biblioteca Nueva: 160 .

${ }^{56}$ Bando dictado por el comandante general de Canarias Ángel Dolla Lahoz, el 30 de octubre de 1936. Al respecto, el comandante general, dijo que «se hace preciso el nombramiento de un delegado de mi Autoridad en las Escuelas Normales y Primarias de la Región, con objeto de que las enseñanzas que en ellas reciban los escolares sea la adecuada a los grandes principios que siempre han alimentado la cultura y la historia española, y una garantía del orden».

${ }^{57}$ Nombrado por Orden de 30 de octubre de 1936. BOE. 1936, de 2 de noviembre.

${ }^{58}$ Ferrer Muñoz, M. 1996. «Alzamiento y guerra civil en Gran Canaria». en Jornadas de Historia contemporánea de Canarias. Las Palmas de Gran Canaria: Real Sociedad Económica de Amigos del País: 132. 
pistas o caminos de tierra, las escuelas unitarias eran los únicos lugares de aprendizaje y saber que tenían los niños y niñas. En la escuela de la posguerra, sometida a una serie de controles doctrinales y confesionales, con un sinfín de carencias materiales, los maestros y maestras formaron a la infancia isleña. Además instruyeron a generaciones de niños y niñas que no vivieron directamente la guerra pero sufrieron sus consecuencias. En la enseñanza pública el Estado se limitó a la depuración y reclutamiento de los cuadros del magisterio nacional, así como a la impartición de un currículo inspirado en el nacional catolicismo. ${ }^{59}$

\section{LA DIFUSIÓN DE LOS OBJETIVOS NACIONALSINDICALISTAS}

Desde la enseñanza primaria se adoctrinaba a las niñas sobre su excelsa misión en el hogar y se le despierta la aversión hacia la mujer instruida, descalificando a la mujer intelectual, frente a los raquíticos conocimientos que precisaba como mujer. ${ }^{60}$ Se le veta para el estudio, se le confina al hogar y se le encomienda la transmisión de valores patrios y cristianos a la familia. Se daba la paradoja de que las mujeres eran débiles y estaban en continuo peligro de caer en tentaciones, pero debían guardar los valores de la ideología dominante. Las mujeres dentro de la ideología del régimen eran reprimidas a nivel social, educativo, moral, con campañas pro-autoridad, pro-pureza, pro-moralidad, de ahí los consejos públicos a las madres para que vigilaran a sus hijas, los comportamientos, las modas, todo encauzado a mantener a la mujer recluida en el hogar. Las mujeres tenían que ser recatadas y evitar frecuentar espectáculos públicos que resultaban pecaminosos (cine, teatro, bailes, baños de mar,...), incluso en la casa había que evitar cuadros, libros, periódicos que atentaran a la virtud. Las mujeres se negaban a ella mismas como personas para dedicarse al marido, a los hijos y al hogar. Debían ser abnegadas y sacrificarse por los suyos. Abnegación que les permitía asumir el sufrimiento, las penurias, nada importaba sino la resignación. Las mujeres se encontraba en un plano de subordinación frente al hombre, no se busca la equiparación en ningún nivel, pues se pensaba en un orgullo mal entendido que las desvíaba de su condición femenina. En definitiva, se difundía el modelo de mujer mansa, reprimida, abnegada, dependiente y sumisa. La mujer ideal tenía asignado un único lugar dentro de la sociedad: el hogar. A las isleñas, igual que a otras mujeres del Estado, se les adscribía en exclusividad la función doméstica, dedicadas al hogar y la familia, esquema asumido en la época y desde esa óptica se valora su aportación. ${ }^{61}$

\footnotetext{
${ }^{59}$ Capitán Díaz, A. 2000. Educación en la España contemporánea. Barcelona, Ariel Educación: 253.

${ }^{60}$ Serrano Haro, A. 1946. La escuela rural. Madrid: Escuela Española: 123 y 128.

${ }^{61}$ Navarro Artíles, F. 1948. «La mujer y el hogar». Arriba España. Santa Cruz de Tenerife, enero. Ibídem. «Las profesiones y la feminidad». marzo.

Hispania Sacra, LXVI

133, enero-junio 2014, 337-363, ISSN: 0018-215X, doi: 10.3989/hs.2013.055
} 
En ningún momento se descuidó la educación de las mujeres en Canarias siguiendo los dictados oficiales. La Sección Femenina desarrolló una amplia actividad en diversos campos y puso todo su empeño en alcanzar sus objetivos formativos. Las afiliadas a la Sección Femenina se formaban en una serie de contenidos comunes en toda España. Ese aprendizaje comprendía las Enseñanzas Domésticas (pedagogía familiar,puericultura y economía doméstica), la formación religiosa (preceptos morales, dogmas y liturgia), la Doctrina, Moral y Estilo Nacionalsindicalista (Principios del movimiento y teoría de la falange), la Educación Física, Gimnasia y Deportes (pruebas físicas para fortalecer a las mujeres) y la Música (coros y danzas). En ambas provincias insulares desde 1936 se pusieron en marcha diversas escuelas para atender a la formación de las mujeres. Así impulsaba, como en el resto del estado español, cursos de formación, donde se incorporaban elementos de un cierto nivel cultural, aunque bien adoctrinados, respondiendo a las nuevas exigencias para la educación femenina. Organizaron cursos de formación para las mujeres adultas, y de perfeccionamiento para las instructoras locales. El modelo que se transmitía se basaba en los valores tradicionales de la sociedad decimonónica, donde las mujeres eran la célula esencial en la familia patriarcal.

Siguiendo las disposiciones oficiales organizaron el Servicio Social obligatorio para todas las jóvenes a través del cual se impartían sus enseñanzas en los centros de la Sección Femenina. ${ }^{62}$ El Servicio Social era el equivalente al servicio militar para los hombres pero con una duración menor. Se trataba de un curso de seis meses en la que se instruía a las mujeres de acuerdo a los postulados del régimen y que era requisito para acceder a una titulación, puesto laboral, expedición de títulos académicos, carnet de conducir, pasaporte, etc. ${ }^{63}$ La falta de personal y presupuestos provocó que no se lograran los objetivos pretendidos. Hubo exenciones y en algunos casos se redujo el tiempo del servicio, a veces duraba tres meses, por ejemplo para las mujeres que tuvieran estudios de bachillerato. Había normas que regulaban el Servicio Social y sus exenciones. ${ }^{64}$ El Servicio Social se exigía a las mujeres solteras de edades comprendidas entre 17 y 35 años. Estaban exentas las casadas y solteras mayores de 35 años. Además, según los decretos 378 y 418 , las que no justificaran la realización del mismo, mediante el correspondiente certificado, eran suspendidas de empleo y sueldo hasta que le dieran cumplimiento. El Servicio Social se podía realizar en régimen de internado,

${ }^{62}$ El Servicio Social para las españolas se estableció por Decreto de 7 de octubre de 1937 (BOE 11 de octubre) y su Reglamento por Decreto de 28 de noviembre de 1937 (BOE 20 de noviembre). «La imposición del «Servicio Social» a la mujer española ha de servir para aplicar las aptitudes femeninas en alivio de los dolores producidos en la presente lucha y de las angustias sociales de la posguerra».

${ }^{63}$ Gaceta de Tenerife. 1938. Santa Cruz de Tenerife, 10 de febrero.

${ }^{64}$ «Normas sobre el Servicio Social de la Mujer». 1938. Gaceta de Tenerife, 26 de febrero; «Auxilio Social. Como lo prestaran las funcionarias municipales de esta capital». 1938. Gaceta de Tenerife, 25 de febrero. 
con una duración de tres meses en los centros de la Sección Femenina, o de forma ordinaria durante seis meses en centros benéficos, compaginados con un programa teórico, sustentado en asignaturas de hogar y en adoctrinamiento político y religioso. Desde el Consejo Nacional de la Sección Femenina se reconocía la importancia y la labor desarrollada a través de esta prestación femenina y la prensa local reproducía los balances ${ }^{65}$. Las maestras debían realizar el Servicio Social para poder desempeñar sus funciones docentes.

Además en los centros propios destinados a la juventud femenina también incidían en las cuestiones de orden religioso, cultural y preparación para la vida del hogar. Había que hacer más femeninas a las mujeres y de ahí el esmero en introducir contenidos específicos para ellas ${ }^{66}$ Las mujeres debían ser instruidas, no para sobreponerse al marido ni para equipararse con él sino para mantenerse con dignidad a su lado.$^{67}$ El ideario se propagó en los colegios de todo el estado con la incorporación de materias específicas, o a través de los cursillos de «Formación del Espíritu Nacional» impartidos por las encargadas de la Sección Femenina de Falange. Aunque muchas mujeres fueran analfabetas, se les enseñaba a bordar, coser, decorar y atender la casa, a ser educadas y cuidar los hijos. Además, el público femenino recibía los mensajes subliminales por medio del cine, teatro, novelas rosas y canciones. Las enseñanzas de política, religión y gimnasia eran obligatorias en los centros de enseñanza primaria, media, universitaria y en las Escuelas de Magisterio durante todo el periodo franquista. Estas enseñanzas eran impartidas por miembros de la Sección Femenina que se hallaban repartidas por toda la geografía española. Estaban instruidas en los nuevos postulados pero muchas de ellas carecían de preparación académica. El objetivo consistía en consolidar su «adoctrinamiento doméstico» desde las escuelas y, por ello, impartían formación política, formación familiar y social, puericultura y enseñanzas del hogar.

\section{LAS ESCUELAS Y CENTROS EN SU AMPLIA RED FORMATIVA}

A la Sección Femenina se le adjudicó la formación social y política de todas las mujeres españolas. Para cumplir con sus objetivos fundaron Escuelas de Formación y Escuelas Hogar. ${ }^{68}$ También impartían las enseñanzas de Educación Física, Artesanía, Divulgadoras Sociales y Enfermería ${ }^{69}$ Igualmente

\footnotetext{
${ }^{65}$ Falange. 1950. Las Palmas, 20 de enero.

${ }^{66}$ Sección Femenina de FET y JONS (1942). Lecciones para los Cursos de Formación e Instructoras de Hogar, Madrid: 16.

${ }^{67}$ «La mujer y el Hogar». 1938. La Mujer de Acción Católica. n 18 . Diciembre: 15.

${ }^{68}$ Suárez Fernández, L. 1993. Crónica de la Sección Femenina y su tiempo. Madrid: Nueva Andadura: 108 .

${ }^{69}$ Ibídem: 109-111. 
crearon centros de formación de mandos y profesorado, estableciendo Escuelas de Formación y Capacitación del Profesorado y de Formación de Profesionales en distintos niveles ${ }^{70}$. Se sobrevaloraba el rol tradicional de las mujeres y hacia su desarrollo enfocaban sus objetivos. De tal forma que se prestigió el aprendizaje de materias vinculadas con el mundo doméstico que se rotularon como «Ciencias Domésticas», siendo las materias básicas para la formación de las mujeres. ${ }^{71}$

En Santa Cruz Tenerife la Sección Femenina se implicó en la educación desde los primeros momentos. A la vez que inauguraron sus locales abrieron aulas para impartir enseñanza Primaria y secundaria, cursos de corte y confección, puericultura, idiomas y secretariado. La prensa anunció la apertura de curso de la Universidad Nacional Obrera. ${ }^{72}$ La preocupación por la formación de las mujeres para la vida del hogar fue asumida de tal modo que los propios mandos y las afiliadas recibían formación específica. Para desarrollar el rol tradicional «la Sección Femenina va celebrando su plan de formación, con los cursos provinciales y nacionales a los que asisten también continuamente camaradas de las islas a fin de que cada una, conociéndolas todas, pueda escoger vocacionalmente su puesta de servicio». ${ }^{73} \mathrm{El}$ espacio reservado para las mujeres estaba en el ámbito privado, en la atención a la familia y las cuestiones del hogar. Para tal cometido había que prepararla. Bajo la mirada del fascismo no se entendía el rol de las mujeres de otra forma, incluso la propia prensa educativa incidía en ello. ${ }^{74}$

\section{LAS ESCUELAS HOGAR}

Las Escuelas Hogar constituyeron lugares formativos para las jóvenes isleñas. Había catorce centros en el Archipiélago. Igualmente se organizaron las escuelas de formación. En 1940 funcionaban 27 escuelas con la asistencia de 366 mujeres. En las fábricas y centros de trabajo donde había empleadas se encargaban de facilitarles instrucción una vez concluida la jornada de laboral. Así cabe señalar el caso de las fábricas de tabaco o el de las fosforeras, como fue el caso de la Fosforera Canariense, donde las productoras, después de terminada la jornada de trabajo, recibieron instrucción «desde las primeras letras hasta su formación nacionalsindicalista». Las falangistas no ignoraban la importancia de la formación en clave del adoctrinamiento, máxime cuando buena parte de las mujeres de los sectores populares eran analfabetas o apenas habían estado

\footnotetext{
${ }^{70}$ El Día. 1942. Santa Cruz de Tenerife, 8 de marzo.

${ }^{71}$ «Mirando al Hogar». 1936. Gaceta de Tenerife. Santa Cruz de Tenerife, 29 de octubre.

72 Ibídem.

${ }^{73}$ AHPSCT. Fondo Sección Femenina. Informes del Consejo Provincial (1936-1977).

${ }^{74}$ Escuela Azul.1940. Santa Cruz de Tenerife, 10 de julio; 30 de enero de 1946 y 10 de enero de 1948.
} 
escolarizadas. Por tal motivo tenían planificadas un total de 40 nuevas escuelas distribuidas por los distintos pueblos de las islas.

La educación de las mujeres fue prioritaria para las dirigentes de la Sección Femenina, como hemos aludido en páginas anteriores, sin embargo, en ocasiones, la realidad entorpeció su acción. Las delegaciones provinciales de Canarias no ignoraban el problema de analfabetismo entre la población femenina insular así como la falta de escuelas en muchos pueblos. Este hecho dificultaba sus objetivos porque las maestras eran también delegadas locales de la Sección Femenina y en los pueblos donde no había escuelas para niñas no se podían organizar. Además, en el caso de existir una escuela de niñas tampoco la maestra podía abarcar tanta tarea sola, por superposición de actividades. Añadir que en los pueblos se contaba con afiliadas pero no estaban capacitadas para desempeñar cargos de responsabilidad porque la mayoría de las mujeres carecía de formación y apenas sabían «leer y escribir». ${ }^{75}$

Para asegurarse de que ninguna mujer ignorara su cometido, las delegaciones provinciales insulares de la Sección Femenina - de igual modo que las peninsulares - organizaban cursos y cursillos para todas las mujeres, en los que les enseñaban higiene personal, cocina, hogar y economía doméstica. De forma similar a otras zonas del Estado, en las islas disponía distintos centros repartidos por diferentes lugares del archipiélago. Podemos mencionar los Círculos de Juventudes, Albergues, Campamentos, Escuelas Hogar, Cátedras, Talleres Artesanos, etc.

A partir de 1941 se fundaron las Escuelas Hogar en los centros de enseñanza media y profesional convencidas de la importancia de la formación de las estudiantes para la vida doméstica. ${ }^{76}$ En cada instituto de enseñanza media se estableció una escuela hogar, a cuyo frente se hallaba una directora y una secretaria responsables de organizar las enseñanzas de Educación Física, Política y Hogar. Estas escuelas también tenían la misión de la formación moral de las mujeres y por ello se impartían clases de hogar en otros espacios que no fueran exclusivamente académicos con el objetivo de regenerar a las mujeres. Por ejemplo, en las cárceles se instruía a las mujeres republicanas allí detenidas para influir en la formación moral de las reclusas y recuperarlas para la España nacionalsindicalista. ${ }^{77}$

Además de las actividades señaladas anteriormente, en el Archipiélago se llevó a acabo una amplia gama de acciones culturales, artísticas y campeonatos

${ }^{75}$ AHPSCT. Fondo Sección Femenina. Libro de Actas de Juntas de Regidoras (1940-1943). Junta celebrada el 1 de junio de 1940: 7.

${ }^{76}$ AHPSCT. Fondo Sección Femenina. Informes del Consejo Provincial.

77 «Tarea de la Sección Femenina». 1941. Medina (Revista de la Sección Femenina de la Falange Española Tradicionalista y de las JONS). Madrid, 1 de mayo.

Hispania Sacra, LXVI

133, enero-junio 2014, 337-363, ISSN: 0018-215X, doi: 10.3989/hs.2013.055 
deportivos ${ }^{78}$ Un extenso programa en el que incluían el cine, el teatro, manualidades, música, lecturas dialogadas, hogar, talleres de artesanía. También impartían cursos para profesoras de hogar así como de promoción profesional obrera (artesanía, auxiliar de clínica, empleadas del hogar). Igualmente se realizaban concursos en navidad y el festival de Santa Teresa, la patrona. La colección fotográfica de la Sección Femenina testimonia la variedad de la programación efectuada. Consta de fotografías de los albergues, festivales, conciertos, cátedras, actividades deportivas, artesanía, actividades de clase, clausura de cursos, etc. ${ }^{79}$

\section{LA EDUCACIÓN MUSICAL Y EL FOLKLORE}

La música fue otra actividad importante a la que le dedicaban un espacio importante, con el objetivo de instruir los gustos musicales ${ }^{80}$ porque la Falange quería que se cantara bien y así lo difundía a nivel nacional. ${ }^{81}$ Las canciones regionales y la danza eran expresión del pueblo y respondían a la diversidad cultural de la geografía española. ${ }^{82} \mathrm{Se}$ consideraba de mal gusto otro tipo de canciones, incluso estimadas perjudiciales, hasta el extremo de que podían herir la sensibilidad y por ello se prohibían.$^{83}$ Las representantes de Canarias asistían a los cursos organizados por la Sección Femenina en Medina del Campo. En ocasiones los cursos se organizaron por zonas geográficas atendiendo a cierta afinidad en los géneros musicales, como sucedió con el cursillo de educación y preparación musical para la «gran concentración» de la Sección Femenina en la Escuela de Jerarquías de Medina del Campo, donde participaron 20 camaradas del sur, dirigido por el maestro Rafael Benedito. ${ }^{84}$

Desde las altas esferas de la Sección Femenina se le concedía importancia a la música popular y por este motivo se hallaba entre sus objetivos la difusión de la música tradicional. Desde la óptica oficial en cada una de las regiones históricas se desarrolló una labor de rescate y divulgación. Tampoco podemos ignorar que la Sección Femenina en ambas provincias canarias (Las Palmas y Santa Cruz de Tenerife) se implicó, del mismo modo que lo hicieron otras homónimas en otros lugares del estado español, en la recuperación del folklore,

${ }^{78}$ AHPSCT. Delegación Provincial de la Sección Femenina.

79 Ibídem. Colección Fotográfica. AHPLPGC. Delegación Provincial de la Sección Femenina. Colección Fotográfica.

${ }^{80}$ Sección Femenina. 1944. Anuario.

81 «El arte musical en la nueva España». 1940. Semanario nacionalsindicalista. 27 de enero.

82 «Música, danza, magníficos exponentes del alma de los pueblos que se asoman en sus ritmos. Por ello resucita la danza la Sección Femenina». Consigna. 1940. Revista de la Sección Femenina, diciembre.

${ }^{83}$ 1942. Revista Mandos. Frente de Juventudes. Madrid, marzo.

${ }^{84}$ «Falange». 1939. Las Palmas, 3 de marzo. 
aunque unificando y aglutinando tanto la indumentaria (el traje de Teror para la provincia de Las Palmas y el traje de La Orotava para la provincia de Santa Cruz de Tenerife) como el repertorio musical tradicional representativo de las respectivas provincias. Los Coros y Danzas de las respectivas delegaciones provinciales de la Sección Femenina se trasladaban para actuar en los pueblos y de esa forma difundir el folklore. Los coros y danzas actuaban con su repertorio en festivales y conmemoraciones. Además se desplazaban para participar en los actos que se celebraban en los pueblos y en ocasiones a otras islas ${ }^{85}$ En las delegaciones locales insulares funcionaban las secciones musicales, organizando también coros y danzas. Este hecho favoreció el desarrollo de la música a nivel educativo ya que sus enseñanzas se incorporaron también a otras instituciones formativas como las escuelas hogar, servicio social, albergues además de los centros educativos. ${ }^{86}$

Además de centros propios, las organizaciones juveniles de Falange tenían potestad para impartir enseñanzas en los centros escolares y en los centros de trabajo. El plan de formación, de acuerdo con sus postulados, consistía en proporcionar a las niñas la educación necesaria que precisaba una mujer. Las instructoras impartían conferencias de religión, nacional-sindicalismo, clases de dibujo, música, cocina, hogar, labores, etc. Además se realizaban excursiones a modo de convivencia. Todas las actividades guardaban una estricta separación de sexos. Así la OJE programaba actividades para los varones, siguiendo fielmente el ideario falangista masculino. La educación que trazaba la Sección Femenina para las mujeres era diferente a la de los hombres, en relación con sus características psicobiológicas.$^{87}$ En función de la natural inferioridad intelectual de la mujer se imponían unas normas y unos contenidos exclusivamente femeninos. No se prohibía expresamente el acceso de la mujer a la educación secundaria y superior, pero se ridiculizaba a las mujeres cultas llamándolas «antimujeres», porque el sitio de las mujeres era el hogar. En caso de que la mujer desviara su natural vocación debía encaminarse a carreras tales como Magisterio o Filosofía y Letras, porque las ciencias abstractas eran incompatibles con el sexo femenino. ${ }^{88}$

${ }^{85}$ En Gran Canaria cabe destacar en lo que respecta a la música popular a la rondalla «Estrella Azul» integrada por las trabajadoras de la Fosforera Canariensis, que bajo los auspicios de dicha fábrica ofrecían su variado repertorio en distintos festejos populares. La rondalla compuesta por jóvenes de ambos sexos contaba con una sección de bailes y cantos típicos canarios. Desde las páginas de la prensa se comentaba el cultivo sano del arte y cómo «se alejan voluntariamente de otras diversiones nocivas que atrofian el espíritu y la inteligencia».

${ }^{86}$ Falange. 1939. Las Palmas, 3 de marzo.

${ }^{87}$ SF de FET y las JONS. 1942. Lecciones para los cursos de Formación e Instructoras de Hogar. Madrid: 16.

${ }^{88}$ Medina. 1942. Revista de la Sección Femenina. Madrid, 3 de mayo y 19 de julio.

Hispania Sacra, LXVI

133, enero-junio 2014, 337-363, ISSN: 0018-215X, doi: 10.3989/hs.2013.055 
Igualmente, las jóvenes de la Sección Femenina de provincias asistían a cursos de formación y para ello debían desplazarse a Madrid o al lugar convenido. También acudían junto a otras regiones cuando se realizaba la Demostración Nacional del Frente de Juventudes. En 1944 las camaradas de Tenerife y Las Palmas viajaron a Madrid. Allí se alojaron en los Conventos de las Reparadoras y asistieron a conferencias, cursos, visitaron museos, parques, etc. ${ }^{89}$

\section{LA EXTENSIÓN DE LA FORMACIÓN EN LAS ZONAS RURALES}

Las maestras ejercieron una importante labor, atendiendo a la formación de niños y niñas dentro de la institución escolar, dando respuesta no sólo a las necesidades instructivas de la población desescolarizada sino también inculcando los valores establecidos tras la implantación del régimen dictatorial. Su protagonismo fue aún más destacado dentro de las áreas rurales.

«La figura de la maestra es potencialmente muy fuerte, a ella se la encomienda la formación del resto de mujeres. El contexto rural se consideró como el más virgen y puro. De este modo, adquiere especial importancia la maestra rural como motor regenerador de la sociedad rural. Tanta importancia se concedió a la vida rural que la Sección Femenina, por medio de la Hermandad de la Ciudad y el Campo, puso en marcha la organización de las Granjas Escuelas de Orientación rural de la mujer». ${ }^{90}$

Se formaba a las maestras, a través de cursos especiales, para que instruyeran a las mujeres de clases populares. El interés por la preparación de las maestras para que desempeñaran la labor de educar a las mujeres así como para ocupar cargos de dirección fue importante, hecho comprensible dado el escaso interés de las mujeres y la necesidad de dirigentes que existía en aquel momento. Todas las maestras afiliadas a la Sección Femenina podían asistir a los cursos y por delegación el Ministerio de Educación Nacional les concedía el permiso reglamentario. Los cursos a los que asistían eran de delegadas y regidoras provinciales, instructoras de educación física, jefas de escuela hogar, instructoras elementales de juventud, etc. ${ }^{91}$ En Gran Canaria entre los años 1940 y 1942 se realizaron cursos para maestras con una alta participación. Por ejemplo se realizó

\footnotetext{
${ }^{89}$ «Han llegado nuestras camaradas». Medina. Revista de la Sección Femenina. Madrid, 9 de julio de 1944.

${ }^{90}$ Rabazas Romero, T. y Ramos Zamora, S. 2006. La construcción del género en el franquismo y los discursos educativos de la Sección Femenina. Encounters on Education. Volumen 7, Fall: 51.

${ }^{91}$ Falange. 1942. Las Palmas, 3 de marzo. La prensa recogió el anuncio de que el 9 de marzo comenzaba el curso de Instructoras Elementales provisionales de la Sección Femenina del Frente de Juventudes.
} 
un curso de Escuela del Hogar al que concurrieron 47 maestras y otros cursos de formación para maestras especializadas con la asistencia de 59 maestras. ${ }^{92}$

Si bien en un primer momento estos programas de formación se centraron en las zonas urbanas. Paulatinamente se extendieron a las áreas rurales, donde se concentraba un alto porcentaje de trabajadoras analfabetas. Por ello se impartieron cursos de divulgadoras rurales en ambas provincias insulares, que eran conocidos con el nombre de «Cátedras Ambulantes». Dichos cursos comenzaron a realizarse a partir de 1946 en otras zonas españolas. En las islas se organizaron una década más tarde. En este sentido la Sección Femenina realizó una labor formativa prioritaria destacando la iniciativa de las «Cátedras Ambulantes». ${ }^{93}$ Como en otras partes de la geografía rural española en Canarias estas escuelas itinerantes ofrecían servicios educativos, asistenciales y adoctrinadores a la población femenina rural. La labor divulgativa que realizaban las mujeres de la Sección Femenina traspasó las áreas urbanas y llegó hasta los lugares más alejados de las islas..$^{94}$ Los programas formativos se dirigieron al colectivo femenino rural conscientes de la importancia de su formación para la vida doméstica. ${ }^{95}$ En cada provincia insular funcionaba una Cátedra de la Sección Femenina, con sede en la capital respectiva: una en Santa Cruz de Tenerife y otra en Las Palmas. En cambio no se extendieron por el Archipiélago los Albergues y Campamentos de Juventud, sólo funcionaba uno en Arinaga (Gran Canaria).

En 1942 en las zonas rurales de Gran Canaria contaban con 279 campesinas inscritas, producto del empeño por reactivar a las trabajadoras del sector agropecuario ${ }^{96}$ En un solo día consiguieron que se sindicaran 124 productoras del campo. También para impulsar el cuidado de ganado menor realizaron cursos de cunicultura, donde participaron 40 mujeres. Además repartieron conejos de raza rusa a las campesinas en los pueblos de Agüimes y Tenoya. ${ }^{97}$

Así mismo elaboraron un fichero de industrias rurales. No ignoraron la trascendencia de las artesanías como recurso para la subsistencia familiar. Las visitadoras realizaron censos de los hogares artesanos, contabilizando 133 hogares artesanos y 274 talleres individuales. El aprendizaje de las labores artesanas era uno de los objetivos en la formación de las mujeres dada la importancia que estas actividades tenían en el hogar. La Sección Femenina se preocupó no sólo por la instrucción sino también por el rescate y mantenimiento de las

\footnotetext{
${ }^{92}$ Intensa labor de nuestra Sección Femenina. 1942. La Falange. Las Palmas, 1 de octubre.

${ }^{93}$ Marías Cadenas, S. 2006. La Sección Femenina en el medio rural: auxilio material, formación de la mujer y control social. Universidad de Zaragoza: 8.

94 «La instrucción de la mujer rural». 1945. Escuela Azul, Santa Cruz de Tenerife, 20 de mayo.

${ }_{95}$ Escuela Azul. 1946. Santa Cruz de Tenerife, 20 de febrero.

${ }^{96}$ «Intensa labor de nuestra Sección Femenina». 1942. La Falange. Las Palmas, 1 de octubre.

${ }^{97}$ Ídem.
} 
manufacturas existentes. Con motivo de la visita de Pilar Primo de Rivera - en marzo de 1942 - hicieron una exposición de industrias artesanas de la isla de Gran Canaria en las salas del Cabildo.$^{98}$ La Delegada Nacional en su visita a Canarias pronunció charlas sobre las ventajas de las «industrias rurales familiares y caseras». ${ }^{99}$

A partir de 1950 fundaron colegios menores para atender la formación básica (aspecto religioso, cívico-social y cultural) de las jóvenes que llegaban a las ciudades procedentes de las zonas rurales, una especie de acompañamiento y orientación para que siguieran el camino trazado para ellas. En total funcionaron 23 colegios menores en distintos lugares de la geografía española, pero en Canarias sólo funcionó uno radicado en la isla de La Gomera.

\section{Conclusión}

Las consecuencias del franquismo sobre la sociedad española en general y la enseñanza en particular fueron nefastas. En todos los ámbitos se experimentó una involución que no fue reparada hasta la restauración democrática. Con el golpe de estado y la guerra civil se perdió la oportunidad para vertebrarse como una sociedad moderna y se instauró una dictadura militar sustentada por valores tradicionales y principios pedagógicos decimonónicos. El régimen totalitario con influencia falangista, marcado por el nacional-catolicismo, impregnó la vida de la sociedad isleña, de la misma forma que sucedía en otros lugares del solar hispano, al margen de que el archipiélago no fue escenario directo de la contienda pero sufrió sus consecuencias.

En el modelo social gestado en el franquismo en Canarias, en particular, y en España, en general, se operaron transformaciones ideológicas tanto en el ámbito público como privado, vinculados con los planteamientos impuestos por el régimen dictatorial. En base a la segregación sexual se adjudicaba a los hombres la actividad pública ejerciendo trabajo remunerado y a las mujeres la privada, dentro del universo del hogar. Unos espacios y unos contornos delimitados de actuación reforzados desde la infancia donde se favorecían las relaciones jerárquicas de género. La década de los cuarenta fueron años nefastos para la educación en Canarias. Añadir las menores oportunidades formativas para las niñas y jóvenes, además de ser apartadas de los centros educativos por la creencia de que la mejor formación para las mujeres estaba vinculada a las actividades domésticas y a su futura vida en el hogar.

98 Pilar Primo de Rivera habla a la Sección Femenina. 1942. Falange. Las Palmas, 3 y 5 de marzo de 1942 .

99 Ibídem.

Hispania Sacra, LXVI 133, enero-junio 2014, 337-363, ISSN: 0018-215X, doi: 10.3989/hs.2013.055 
La Sección Femenina en Canarias reprodujo el prototipo de mujer española, difundiendo en su ideario las virtudes femeninas. En los pueblos de la geografía insular las niñas y jóvenes se adhirieron a sus postulados, incluso en los pueblos pequeños y distantes se organizaron las mujeres según el modelo nacionalsindicalista. A través del servicio social se reforzaba el modelo de mujer. Era una forma de control sobre las jóvenes a la vez que se intensificaba el adoctrinamiento ideológico. La moral católica condicionó la vida de las mujeres, siendo vigiladas para que no transgredieran el orden vigente. El papel de la iglesia fue clave como difusora de los valores cristianos y del modelo de mujer piadosa encarnado en la virgen María. También como forma de contención de conductas indebidas para que se comprometiera con la fe y cumpliera con resignación su misión en la familia. Dios, Patria y Hogar fue la trilogía que marcó a las españolas y cuya educación se orientó hacia la consecución de estos objetivos. Las mujeres eran garantes de la cristiandad en el seno familiar al tiempo que defensoras de los valores de la patria desde el ámbito del hogar.

En este trabajo analizamos de forma sucinta la trayectoria de la educación de las mujeres en Canarias durante el primer franquismo. Esta época supuso un importante retroceso en los derechos de ciudadanía de las mujeres. Se modificó el modelo de mujer y se retomaron estereotipos ancestrales para conformar la identidad femenina basada en la subordinación al patriarcado. Al margen de la involución experimentada con la pérdida de los derechos constitucionales y el retroceso con el modelo de mujer acuñado por el nacional catolicismo, la Sección Femenina desplegó con intensidad su labor educativa en el archipiélago desde 1936 cuya actividad perduró hasta 1976. El 1 de abril de 1977 se liquidaba su papel en sentido amplio, aunque su adoctrinamiento había calado en la mentalidad de generaciones de mujeres. No obstante el modelo hegemónico fue perdiendo vigencia y fuerza entre las mujeres en la medida en que evolucionaba la sociedad española.

\section{BIBLIOGRAFÍA}

Alcalde, M. 1999. Mujeres en el franquismo: Exiliadas, nacionalistas y opositoras. Barcelona, Flor del Viento.

Alted Vigil, A. 1991. «Las mujeres en la sociedad española de los años cuarenta», en Las Mujeres y la Guerra Civil Española. Madrid: Ministerio de Asuntos Sociales/ Instituto de la Mujer.

Ballarín Domingo, P. 2001. La educación de las mujeres en la España contemporánea (siglos XIX-XX). Madrid: Síntesis.

Capitán Díaz, A. 2000. Educación en la España contemporánea. Barcelona, Ariel Educación. 
Campo, S. del. 1974. «Política demográfica de la familia y de la natalidad en España». Revista Sistema, 4: 47-73.

Escolano Benito, A. 2002. La educación en la España contemporánea. Madrid: Biblioteca Nueva.

Ferrer Muñoz, M. 1996. «Alzamiento y guerra civil en Gran Canaria». Jornadas de Historia contemporánea de Canarias. Las Palmas de Gran Canaria: Real Sociedad Económica de Amigos del País.

Flecha García, C. 1989. Algunos aspectos sobre la mujer en la política educativa durante el régimen de Franco. Revista Ineruniversitaria de Historia de la Educación, nº 8: 77-98.

Gallego Méndez, M. T. 1998. Mujer, Falange y Franquismo. Madrid, Taurus.

Nielfa Cristóbal, Gloria (Coord). 2003. Mujeres y Hombres en la España franquista: sociedad, economía, política, cultura. Madrid, Ed. Complutense.

González Menéndez-Reigada, A. 1940. Mujeres de España. Santa Cruz de Tenerife: Imprenta Católica.

González Pérez, T. 2009. Los programas escolares y la transmisión de roles en el franquismo: La educación. Bordón, Vol. 61-3: 96.

Guerra Palmero, R. 2007. La Falange en Canarias (1936-1950). Santa Cruz de Tenerife: CCPC.

Marías Cadenas, S. 2006. La Sección Femenina en el medio rural: auxilio material, formación de la mujer y control social. Universidad de Zaragoza.

Payne, S. G. 1997. El régimen de Franco. 1936-1975. Madrid: Alianza Editorial.

Primo de Rivera, P. 1983. Recuerdos de una vida. Madrid: Ediciones Dyrsa.

Rabazas Romero, T. y Ramos Zamora, S. 2006. La construcción del género en el franquismo y los discursos educativos de la Sección Femenina. Encounters on Education. Volumen 7, Fall: 51.

Roca i Girona, J. 1991. «Algunos elementos constitutivos del discurso dominante sobre la mujer en la posguerra española». En M. Nash y S. Tavera (Coord.) Las Mujeres y la Guerra Civil Española. Madrid: Ministerio de Cultura.

Sección Femenina de FET y JONS (1942). Lecciones para los Cursos de Formación e Instructoras de Hogar, Madrid: 16.

Serrano Haro, A. 1946. La escuela rural. Madrid: Escuela Española.

Suárez Fernández, L. 1993. Crónica de la Sección Femenina y su tiempo. Madrid: Nueva Andadura: 1993: 108.

Toboso Sánchez, P. 2009. Las mujeres en el siglo xxi: Igualdad jurídica, discriminación cotidiana. En P. Pérez Cantó, P. (ed.) De la Democracia ateniense a la democracia paritaria. Barcelona: Icaria editorial.

Valcárcel,A. 2000. Rebeldes hacia la paridad. Barcelona, Plaza \& Janes, 2000, pp. 84-85. VV.AA. 2000. Historia de las Mujeres. Sigo xx. Tomo $5^{\circ}$. Madrid: Taurus minor. 